\title{
THE USE OF RESORBABLE PLATES IN FIXATION OF ORBITAL BONE FRACTURES A CLINICAL STUDY
}

\author{
Hussein Abdel Motelep *
}

\begin{abstract}
The aim of this study was to verify clinically the effectiveness of sonic weld $\mathrm{RX}^{\circledR}$ Resorbable plates and pins in stabilizing orbital fractures. Fifteen patients presented with traumatic orbital fractures, 8 males and 7 females, treated with open reduction and internal fixation using resorbable plates and pins. The pins were activated through ultrasound apparatus to be fixed to bone and welded to the plates. Postoperatively, the fixed bone remained stable enough to allow complete healing with minimum complications. No need for second operation to remove the plates as they are resorbable. Accordingly, Sonic weld resorbable plates and screws system is reliable in treatment of non-stress bearing orbital fracture.
\end{abstract}

\section{INTRODUCTION}

Internal fixation of maxillofacial skeleton is the standard method of treatment of facial fractures or bone fixation after orthognathic surgery. Metallic plates and screws have become the routine method of stabilizing the craniofacial skeleton. They are reliable and have a low incidence of complications ${ }^{(1)}$. Disadvantages of metal fixation, however, include unacceptable palpability, exposure intraorally, passive migration, and distortion of future magnetic resonance images (MRI) and computed tomograms (CT) ${ }^{(2)}$. Titanium particulate matter may be shed into the adjacent tissues and has also been found in regional lymph nodes ${ }^{(3,4)}$. Furthermore, it needs a second operation to remove specially in growing child ${ }^{(5)}$.

It is ideal to have bio-resorbable material that only supports the bony fragments during healing and resorbs fully once healing is completed. The resulting metabolites should not cause any local or systemic disorders. LactoSorb is a copolymer of poly-L-lactic and polyglycolic acid, in a ratio of $82: 18 \%$. The copolymer is structured to provide adequate strength for 6-8 weeks and to allow a resorption time of 9-15 months. It is metabolized in the citric acid cycle and eventually excreted by the lungs as carbon dioxide and water ${ }^{(6)}$.

Various polymers have been investigated including polylactic acid (PLA) and polyglycolic acid (PGA). Biodegradable fracture-fixation devices have been used in the maxillofacial region by many authors with varying degree of success and complication ${ }^{(7,8)}$. Nieminen et al. $2004^{(9)}$ tested the tissue reactions and mechanical strength of a novel biodegradable craniomaxillofacial plating system, Inion CPS trade mark, in the course of degradation. Plates and screws composed of L: -lactide, D: -lactide and trimethylene carbonate. They concluded that, the plates and screws examined maintain adequate strength for the healing period of a bone fracture or osteotomy, producing no harmful foreign body reactions.

The use of resorbable plates is more or less accepted in the maxilla and midface. On contrary, its use in the mandible is controversy ${ }^{(10)}$. Recently, some articles have been published addressing the use of resorbable plates in the treatment of mandible fracture or after osteotomy ${ }^{(11)}$. Fixation of the plates with resorbable screws requires tapping a thread. This makes the application of resorbable plates very difficult, especially in the thin bone of the midface.

\footnotetext{
* PhD, Consultant and Head of Department of Maxillofacial Surgery, Nasser General Hospital.
} 
To avoid this additional step and facilitate the application of a resorbable system, sonic weld was introduced ${ }^{(12,13)}$. A new application system by welding a special configured Resorbable pin though ultrasound may overcome the disadvantages of thread tapping. With the advantage of only a 2-step procedure, without cutting a thread into the bone, the Resorbable pin is welded in the corticospongy structure of the bone, using an ultrasonic tool ${ }^{(14)}$. The ultrasound welding process allows the Resorbable material to penetrate deeply into the bone structures, taking firm hold to generate a threedimensional primary stability ${ }^{(15)}$.

\section{PATIENTS AND METHODS}

The study consisted of 15 patients, with their age ranged from 3 to 42 years. Seven patients were children under the age of 12 years, while the rest were adults. Sex distribution of children was 4 females and 3 males, while for adults it was 5 males and 3 females. All patients presented with traumatic orbit fracture due to fall, road traffic accident (RTA), Sports or interpersonal fight.

The patients were preoperatively evaluated clinically and radiographically (CT). Ethical clearance and informed consent were obtained.

Clinical examination of patients with orbital fractures include periocular tissues and ocular examination. The periocular tissues were examined for periocular swelling, proptosis (acute stage), enophthalmos (later stage and large fracture), ecchymosis, chemosis, V2 hypesthesia, and subconjunctival hemorrhage. Complete ocular exam included globe integrity, eye pressure, ocular motility, pupil exam, visual field, slit lamp ocular exam, retinal exam, and external exam were done for all patients.

For any obvious globe rupture or concern, $\left(360^{\circ}\right.$ of subconjunctival hemorrhage, misshapen pupil (peaked, corectopia), and flat anterior chamber), immediate ophthalmology consultation was done.
Elevated eye pressure from an orbital compartment syndrome (orbital swelling and retrobulbar hemorrhage) can lead to optic neuropathy and blindness. Accordingly, Pressures below 40 $\mathrm{mmHg}$ were treated with eye pressure lowering drops. However, if conservative therapy failed, a canthotomy and cantholysis were considered.

A slit-lamp examination was performed for further evaluate the cornea and retina. This can detect associated injuries such as corneal abrasions, lens dislocations, hyphema, and retinal detachments.

Assessment of extraocular movement was done with special consideration to children due to the so-called white eye syndrome. Since greenstick fractures are more common in children, these fractures can cause a trapdoor effect and muscle impingement. These patients may also have pain with eye movement, nausea, vomiting, and bradycardia that can mimic the symptoms of a closed head injury.

CT Imaging of the entire face was performed. Coronal and sagittal and three-dimensional (3D) were done for all patients. The medial wall was best visualized in a bone window axial view. The sagittal view allowed for assessment of the orbital floor. Both coronal and sagittal views were used to assess the orbital soft tissue and evaluate for fat herniation or ocular muscle entrapment.

- Inclusion criteria: patients with orbital fractures.

- Exclusion criteria: major orbital wall defects which need reconstruction, Patients with repeated ocular trauma (boxers), only seeing eye and patients not fit for surgery.

\section{Surgical technique:}

All the fractures were treated with resorbable fixation sonic weld RX system (Martin MedizinTechnik Company, Tuttlingen, Germany). The material used was a resorbable copolymer of poly-L-lactic and polyglycolic acid (each 50\%). 
The copolymer is structured to provide adequate strength for 6-8 weeks and to allow a resorption time of $9-15$ months.

The patients were anesthetized under general anesthesia through endotracheal intubation. Subtarsal incision for infra-orbital approach, eyebrow incision for frontozygomatic approach and sub brow incision for upper margin approach were done. Reflection of the flap and exposure of the fractures followed by open reduction and internal fixation.

The plates were heated in water bath for a few minutes to be malleable and then adapted to the fractured bone segment until it became hard. The plates were fixed in the underlying bone by Resorb $x ®$ pins of diameters $1.6 \mathrm{~mm}$ and 4,5 or $7 \mathrm{~mm}$ length according to each case.

First, a drill hole was made then the pin was picked up with the sonotrode tip, applied and activated with ultrasound that softened the pin to go in the drilled hole and to melt with the plate. In all patients, two plates were used for fixation, one at the infra-orbital rim and another one at the supraorbital rim or frontozygomatic fracture fig 1,2.

\section{Postoperative care:}

Instructions were given regarding symptoms of retrobulbar hemorrhage such as worsening pain, sudden swelling, or vision loss for immediate recall.

Elevating the head of bed and Cold packs to decrease postoperative pain and edema were applied early after surgery. Topical ophthalmic ointments were helpful to moisturize the cornea. Nose blowing and heavy lifting was not recommended for at least 2 weeks following surgery.

Postoperative follow up clinically the $2^{\text {nd }}$ day, two weeks, 3 months, 6 months and one-year for pain, edema, soft tissue healing, wound infection, stepping, bone stability, or any adverse reaction. Radiographically (CT) was taken the second day of surgery, after 3months, 6 months and one year

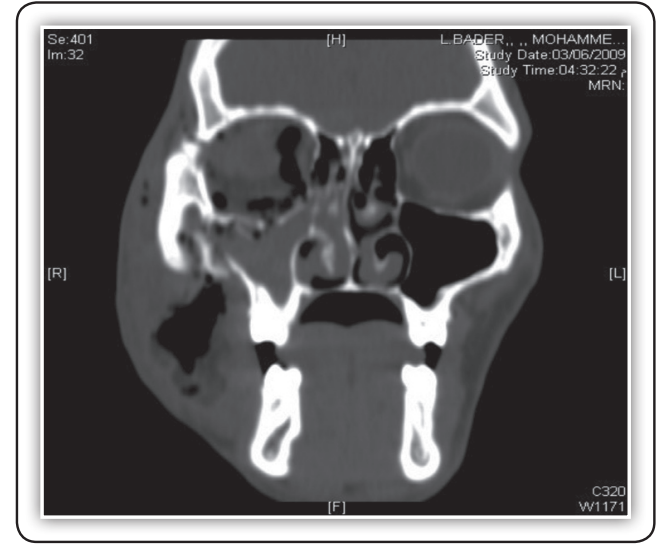

FIG (1) Orbital fracture

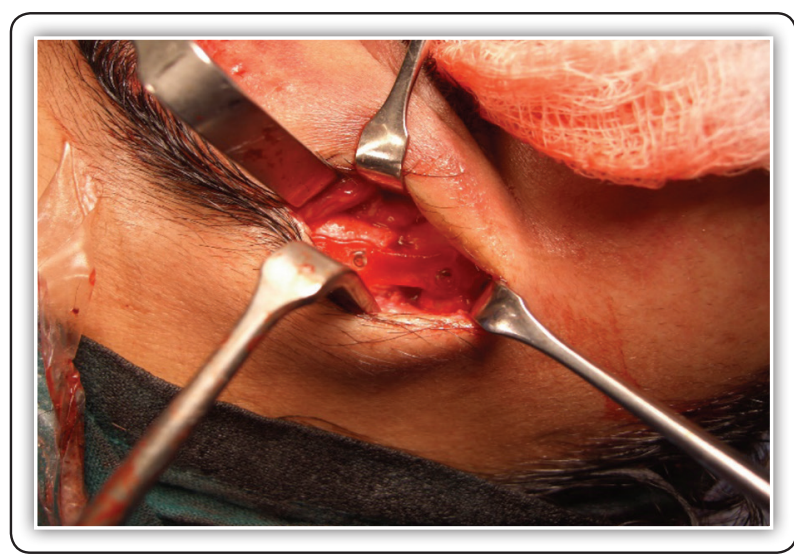

FIG (2) Operative photograph of frontozygomatic fracture treated with resorbable plate and resorb $\mathrm{X}$ screws.

postoperatively to verify reduction, stability and healing of bones.

\section{RESULTS}

\section{Evaluation of the system intraoperatively:}

All pins were successfully handled and fixed with no incidence of fracture and all the plates showed stability after welding. There was some difficulty of handling only in the early phase of the study but as experience was gained the handling was greatly improved. Also, the fixation of the plate to the supra-orbital rim was very easy, but the application of the plate (the adaptation and fixation) in the infraorbital region was more difficult. 


\section{Evaluation of the system postoperatively:}

\section{Clinical results:}

The results of this study showed that the postoperative clinical manifestation like pain and edema resolved within the normal range of time (1 to 2 weeks). No infection occurred except only one patient $(7 \%)$. This patient had soft tissue infection due systemic disease (diabetes mellites) which was managed conservatively with antibiotics and instructed to follow his medications meticulous. This patient showed good clinical results in the other clinical aspects. Soft tissue healing was uneventful with no case of wound dehiscence or allergic reaction. All the patients had good stability without any step formation, disfigurement or movement of fractured bone during the follow up periods for one year. There was no incidence of iatrogenic post-operative sensory disturbance nor ocular complications. The palpability of the plates gradually disappeared by the end of the year.

\section{Radiographic results:}

Postoperative CT was taken the 2nd day, after 3 months, 6 months and one-year. x-ray follow up did not show the plates. All patients $(n=15)$ showed good reduction and alignment of the osseous margin of the orbit without any stepping or displacement of the reduced fractured bones (stable) during the follow up periods. We could only observe the fracture line healing. Bone healing was complete one year postoperative.

\section{DISCUSSION}

Resorbable fixation system has the property of complete biodegradation which allows the maxillofacial bones to continue their physiological growing ${ }^{(16,17)}$.

But the use of biodegradable screws has a number of limiting factors: poor mechanical stability, difficult handling properties, and timeconsuming fixation. The tapping of threads takes a long time and limits easy handling, in particular for small diameter screws, and the insertion is limited by the relation of the axis of the screw to the osteosynthesis plate ${ }^{(18,19)}$.

The aim of the development of ultrasound aided pin fixation was to overcome the drawbacks of conventional resorbable system by creating a new way of linking the osteosynthesis plate and the bone. A specially designed pin is inserted in the drill hole using ultrasound, which fixes the pin into bone structure using a melting (welding) process. At the same time, the pin and the osteosynthesis plate weld together. Because they are welded, the pins can be inserted even if there is a difference in axis between the pin and the osteosynthesis plate. Critical torque forces on screws are avoided, and there is no need for thread tapping. These advantages lead to improved handling and shortened osteosynthesis times ${ }^{(20)}$.

These advantages were found in this study except that the application was difficult in areas with little exposure as the infra-orbital rim. This difficulty was not related to screw fixation but rather to the adaption of the softened plate to an irregular small bone. But this disadvantage is present in all resorbable plates ${ }^{(21,22)}$.

The strength and stability of sonic weld fixation during this clinical study match with Pilling et al $2007^{(23)}$ who demonstrated that the technique of "welding" a resorbable miniplate to bone with pins results in superior strength over using conventional resorbable screws. This concept was further supported by Buijs et al $2009^{(24)}$ because they noted 11.5 times higher mean values for tensile strength, stiffness, and side bending with the SonicWeld Rx system versus the conventional Resorb-X alone without ultrasound energy.

The bone stability indicated that the SonicWeld $\mathrm{Rx}{ }^{\circledR}$ system was adequate for healing and bone formation to take place. This was in accordance with an experimental study by Kropil et al $2012^{(25)}$ who has proved that sonicweld RX is reliable, noninvasive, quantitative monitoring of bone defect healing. 
The results of this study showed that the postoperative clinical manifestation like pain and edema resolved within the normal range of time.

The soft tissue infection due to systemic disease (DM) was managed conservatively with antibiotics and showed improvement due to proper follow up of instructions. This agrees with Cheung et al $2004^{(26)}$, who showed infection rates with resorbable materials to be from $1.4 \%$ to $10 \%$, including orthognathic and trauma cases.

None of the patients complained of preoperative sensory disturbance nor iatrogenic post-operative sensory disturbance. This disagrees with Degala et al $2013^{(27)}$, who fixed zygomatic and mandibular fractures with biodegradable plates and noted temporary paresthesia in three patients out of thirteen $(23.1 \%)$ both preoperatively and postoperatively. The paresthesia improved over 8 weeks in two patients and over 2 weeks in another patient. The other ten patients $(76.9 \%)$ had no neurosensory changes.

\section{CONCLUSION}

Resorbable plates and pins activated with sonic weld are reliable in stabilizing orbital bone fracture with minimum complications. Although the number of our patients in this study is limited, it was enough to endorse its use in a larger group of patients under close observation.

\section{REFERENCES}

1. Schliephake H, Lehmann H, Kunz U and, Schmelzeisen R. Ultrastructural findings in soft tissues adjacent to titanium plates used in jaw fracture treatment. Int. J. Oral Maxillofac Sur 1993; 22: 20-25.

2. Fiala TG, Novelline RA, Yaremchuk MJ: Comparison of CT imaging artifacts from craniomaxillofacial internal fixation devices. Plast Reconstr Surg 1993; 92: 1227-1232.

3. Moberg LE, Nordenram A, Kjellman O: Metal release from plates used in jaw fracture treatment. A pilot study. Int J Oral Maxillofac Surg 1989; 18: 311-314.
4. Solar RJ, Pollack SR, Korostoff E: In vitro corrosion testing of titanium surgical implant alloys: an approach to understanding titanium release from implants. J Biomed Mater Res 1979; 13: 217-250.

5. Orringer JS, Barcelona V, Buchman SR: Reasons for removal of rigid internal fixation devices in craniofacial surgery. J Craniofac Surg 1998; 9: 40-44.

6. Eppley bL, Morales L, and Wood R. Resorbable PLLAPGA plate and screw fixation in pediatric craniofacial surgery: clinical experience in 1883 patients. Plast Reconstr Surg 2004; 114: 850-856

7. bergsma JE, de bruijn WC, Rozema FR, bos RR and boering G. Late degradation tissue response to poly(L-lactide) bone plates and screws. biomaterials 1995;16: 25-31.

8. Ahmad N, Lyles J, Panchal J, Deschamps-Braly J: Outcomes and complications based on experience with resorbable plates in pediatric craniosynostosis patients. J Craniofac Surg 2008; 19: 855-860

9. Nieminen T, Rantala I, Hiidenheimo I, Keränen J, Kainulainen $\mathrm{H}$ et al. Degradative and mechanical properties of a novel resorbable plating system during a 3-year follow-up in vivo and in vitro. Int J Oral Maxillofac Surg 2004; 33: 240-244.

10. Agarwal S, Gupta A, Grevious M, Reid RR: Use of resorbable implants for mandibular fixation: a systematic review. J Craniofac Surg 2009; 20: 331-339.

11. Ahn YS, Kim SG, Baik SM, Kim BO, Kim HK, et al: Comparative study between resorbable and nonresorbable plates in orthognathic surgery. J Oral Maxillofac Surg 2010; 68: 287-292.

12. Poore MC and Penna KJ. The use of resorbable hardware for fixation of pediatric mandible fracture. Case report. $\mathrm{N}$ Y State Dent J 2008; 74:58-61.

13. Cox T, Kohn MW and Impelluso T. Computerized analysis of resorbable polymer plates and screws for the rigid fixation of mandibular angle fractures. J Oral Maxillofac Surg 2003; 61:481-487; discussion 487-488

14. Carron MA, Zuliani G, Pereira L, Abuhamdan M, Thibault A, et al. Stability of midface fracture repair using absorbable plate and screw system pilot holes drilled and pin placement at angles other than 90 degrees. J Facial Plast Surg. 2014;16: 42-8 
15. Burger BW. Use of ultrasound-activated resorbable PolyDL-lactide pins (SonicPins) and foil panels (Resorb-X) for horizontal bone augmentation of the maxillary and mandibular alveolar ridges. J Oral Maxillofac Surg. 2010;68: 1656-1661.

16. Yerit KC, Enislidis G, Schopper C, Turhani D, Wanschitz F, et al. Fixation of mandibular fractures with biodegradable plates and screws. Oral Surg Oral Med Oral Pathol Oral Radiol Endod. 2002;94: 294-300.

17. Edwards RC, Kiely KD, Eppley BL. Fixation of bimaxillary osteotomies with resorbable plates and screws: experience in 20 consecutive cases. J Oral Maxillofac Surg. 2001;59: 271-276.

18. Neff A, Muhlberger G and Karoglan M et al. Stabilitat der Osteosynthese bei Gelenkwalzenfracturen in Klinik und biomechanischer Simulation (Stability of osteosyntheses for condylar head fractures in the clinic and biomechanical simulation). Mund Kiefer Gesichtschir 2004; 8: 63-74.

19. Ricalde P, Engroff SL, Von Fraunhofer JA and Posnick JC. Strength analysis of titanium and resorbable internal fixation in a mandibulotomy model. J Oral Maxillofac Surg $2005 ; 63: 1180-1183$.

20. Eckelt U, Nitsche M, Muller A, Pilling E, Pinzer T, et al. Ultrasound aided pin fixation of biodegradable osteosynthetic materials in cranioplasty for infants with craniosynostosis. J Craniomaxillofac Surg. 2007;35: 218-21.

21. Carron MA1, Zuliani G1, Pereira L1, Abuhamdan M1, Thibault A1. Stability of midface fracture repair using absorbable plate and screw system pilot holes drilled and pin placement at angles other than $90^{\circ}$. JAMA Facial Plast Surg 2014; 16: 42-48.

22. H.J. becker J, Wiltfang. Merten H.A and. Luhr HG. biodegradierbare Miniplatten (Lactosorb) bei Cranioosteoplatik-experimentelle Ergebnisse am schnell wachsenden, juvenilen Miniturschwein (biodegradable miniplates (lactosorb) in cranio-osteoplasty-experimental results with the rapidly maturing, juvenile minipig). Mund Kiefer Gesichtschir 1999; 3: 275-278.

23. Pilling E, Meissner H, Jung R, Koch R, Loukota R, et al. An experimental study of the biomechanical stability of ultrasound-activated pinned (SonicWeld Rx+Resorb-X) and screwed fixed (Resorb-X) resorbable materials for osteosynthesis in the treatment of simulated craniosynostosis in sheep. Br J Oral Maxillofac Surg. 2007;45: 451-456.

24. Buijs GJ, van der Houwen EB, Stegenga B, Verkerke GJ, Bos RR. Mechanical strength and stiffness of the biodegradable SonicWeld Rx osteofixation system. J Oral Maxillofac Surg. 2009;67: 782-287.

25. Kropil P, Hakimi AR, Jungbluth P, Riegger C, Rubbert C, et al. Cone beam CT in assessment of tibial bone defect healing: an animal study. Acad Radiol. 2012;19: 320-325.

26. Cheung LK, Chow LK, Chiu WK. A randomized controlled trial of resorbable versus titanium fixation for orthognathic surgery. Oral Surg Oral Med Oral Pathol Oral Radiol Endod. 2004;98: 386-397.

27. Degala S, Shetty S, Ramya S. Fixation of zygomatic and mandibular fractures with biodegradable plates. Ann Maxillofac Surg. 2013;3: 25-30. 